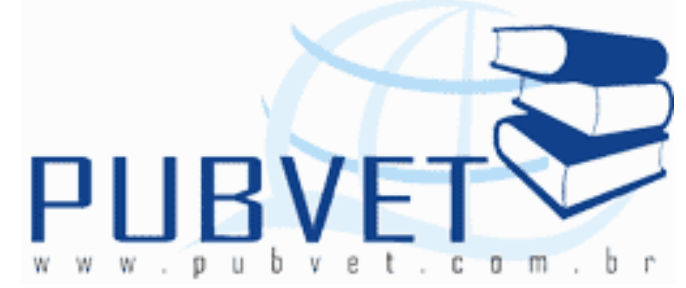

PUBVET, Publicações em Medicina Veterinária e Zootecnia.

Disponível em: <https://doi.org/10.31533/pubvet.v02n11a444>.

\title{
O papel dos filtros e demais equipamentos de um aquário
}

Cássio Roberto Silva Noronha ${ }^{1}$, Gláucia Lucia Moreira², Juliana Garcia Murilo², Jaime Pacheco Duarte Neto2, Wiliam Olimpio Borges²

${ }^{1}$ Professor do Centro Federal de Educação Tecnológica de Bambuí - CEFETBAMBUÍ, Rodovia Bambuí/Medeiros, km 37, Zona Rural. CEP: 39.800.000. CAIXA POSTAL 05, Bambuí - Minas Gerais. Fone: (037) 3431-4900.

${ }^{2}$ Alunos do $1^{\circ}$ ano do Curso Técnico Agrícola com Habilitação em Agricultura e Zootecnia - Concomitantes do CEFET- BAMBUÍ - Centro Federal de Educação Tecnológica de Bambuí. Fone: (037) 3431-4900

2 Aluno do 10 período do Técnico Agrícola com Habilitação em Agricultura e Zootecnia - Pós-médio do CEFET- BAMBUÍ - Centro Federal de Educação Tecnológica de Bambuí. Fone: (037) 3431-4900

\section{RESUMO}

O aquarísmo se caracteriza pela formação de habitat dentro de um recipiente chamado de aquário, onde crescem, desenvolvem e se reproduzem peixes ornamentais. Uma das grandes causas do insucesso do aquarista amador é a não compreensão da complexibilidade deste ecossistema. O Objetivo deste trabalho é estudar os sistemas de filtragem, sejam mecânicos, químicos e/ou biológicos e evidenciar sua importância para o equilíbrio deste habitat.

PALAVRAS-CHAVE: Aquário, peixes ornamentais, filtros, ecossistema. 


\section{The role of aquarium equipments}

The creation of fish in an environment called aquarium, where ornamental fish are raised, bred and grown presents many challenges. One of the big causes of failure in the activity for amateurs is the lack of knowledge about this ecosystem. The main goal of this paper is study the processes involved in aquarium fish raising: filtering (mechanical; chemical or biological) and show its importance for the equilibrium in this delicate habitat.

KEY WORDS: Aquarium, ornamental fish, filters and ecosystem

\section{INTRODUÇÃO}

A filtragem tem por objetivo a purificação da água, visando a qualidade física e química da mesma para melhor condicionamento de seus habitantes (Botelho Filho; Oliveira, 1989).

A filtragem é um processo que retêm substâncias dissolvidas e suspensas na água, e por conseqüência aumenta a oxigenação da mesma e evita a estratificação devido a seu movimento (Botelho Filho; Oliveira, 1989).

Existem dois tipos básicos de filtros. O filtro de funcionamento mecânico, mais indicado para aquários de grande porte, onde a água é impulsionada por um motor de ação centrífuga e o filtro de funcionamento a ar. Neste último, o ar, forma bolhas na água e ao subir leva a água formando uma corrente ascendente. É mais indicado para aquários de pequeno porte (Coleção Animais de estimação, 1986).

O aquário é formado por um conjunto de equipamentos que funcionam interligados entre si com a finalidade de compor um sistema fechado que imita fielmente um ambiente natural. Este ecossistema sofre a interferência direta de fatores internos e externos ao aquário.

Fazem parte de seus componentes: aerizador; aquecedor, termostato, filtro, termômetro, tubo plástico, tampa, pinça, raspador, comedores, ninheira e a rede (Fabichak \& Fabichak, 1985); (Botelho Filho; Oliveira, 1989). 


\section{DESENVOLVIMENTO}

\section{Aquarismo}

Todos nós ficamos impressionados diante da harmonia e beleza de um aquário ornamental que é um quadro vivo mais belo da terra. Ele representa o lago ou mar em miniatura onde podemos observar a vida associada dos peixes e plantas aquáticas, seres secundários (Botelho, 1997).

Aquariofilia constitui mais do que um "hobby", pois várias ciências estão integradas a ela. A zoologia, fisiologia, bioquímica, botânica, higiene, a química e a nutrição, se interligam na construção e manutenção de um aquário (Botelho, 1997).

Sendo assim, é uma ciência que esta condicionada a seis princípios fundamentais. A oxigenação suficiente, a temperatura correta, a alimentação racional, o solo adequado, a vegetação aquática e a luz dosada. Lembrando-se que a qualidade da água é um fator intrínseco a toda atividade aquícola (Botelho, 1997).

\section{Tipos de aquário}

Os aquários são divididos em diversas categorias. Estas categorias se diferenciam pelo tipo de aquário, a finalidade do mesmo, o material de construção entre outras.

Quanto ao tipo são classificados como aquários de água doce ou água salgada (marinhos) (Botelho, 1997).

Outra classificação correlaciona sua função. Nestes se enquadram os aquários de ornamentação, criação, isolamento, hospital, desenvolvimento, depósito e reprodução (Botelho, 1997).

Quanto ao material de construção podemos classificar os aquários como os modernos, confeccionados com vidros e estruturas metálicas de vários tamanhos, e os mais antigos, confeccionados com vidros, normalmente sem estrutura metálica de suporte, de menores tamanhos e às vezes conjugados com cimento, pedra ou outros materiais onde foram construídos (Botelho, 1997). 


\section{Importância e papel dos filtros}

Para se escolher um filtro devemos levar em consideração o tamanho e tipo de aquário e a quantidade e tamanho dos peixes que serão nele acondicionados. Preferencialmente tentar conciliar os três tipos de filtragem, em um ou mais tipos de filtros (ALCON, 2000).

É importante a constante manutenção dos aparelhos por terem alta concentração de resíduos obtidos pela passagem da água do aquário. Existem três formas de filtros. Os filtros mecânicos, químicos e biológicos (Botelho Filho; Oliveira, 1989).

\section{Tipos de filtros}

Os filtros mecânicos são filtros que retêm as partículas submersas com um material de pouco poder de retenção. O Perlon ou Lã de vidro conseguem esta ação (Botelho Filho; Oliveira, 1989).

Os filtros químicos retêm o material dissolvido na água pela ação do carvão ativado por ser um material poroso e conter alto índice de absorção, mas o carvão elimina substâncias importantes como os medicamentos esporadicamente utilizados no aquário. Por isso não se recomenda o uso de carvão ativado em aquários "hospitais". É importante dizer que depois de algum tempo, o carvão ativado satura-se, tornando-se impróprio para tal finalidade tendo assim de ser substituído. Para saber o ponto de saturação pinga-se uma gota de azul de metileno na boca do filtro, se depois de passar pelo filtro a coloração azul aparecer, significa que o carvão está saturado (Botelho Filho; Oliveira, 1989).

O filtro biológico trabalha com um excelente processo em que há uso de bactérias para a decomposição das substâncias. Estas bactérias oxidam a amônia os fosfatos e outros compostos nitrogenados transformando-os em substâncias não prejudiciais (Botelho Filho; Oliveira, 1989). 
Vidal Júnior, 2006, recomenda a utilização de substratos alternativos como base para fixação das bactérias como rolinhos de tela de mosquiteiro ou mesmos "bob`s" de cabelo.

\section{Outros Equipamentos de aquário}

Alguns equipamentos são indispensáveis na composição de um aquário tendo em vista que alguns não são utilizados freqüentemente e sim em determinados momentos.

Porém todos os equipamentos descritos neste trabalho são de muita importância para que a vida de todos os seres existentes no aquário seja saudável e duradoura (Fabichak \& Fabichak, 1985).

Os principais componentes do aquário são:

Aerizador - Também chamados de vibrador ou bomba, possui a função de oxigenação e filtração da água do aquário, sendo o mais utilizado o vibrador (Fabichak \& Fabichak, 1985).

Aquecedor - Serve para manter a boa temperatura da água, que deve estar entre $20^{\circ} \mathrm{C}$ e $28^{\circ} \mathrm{C}$, dependendo da espécie de peixe presente no aquário e q quantidade de água do mesmo. A resistência do aquecedor é semelhante a de um chuveiro elétrico (Fabichak \& Fabichak, 1985).

Termostato - Geralmente é conjugado com o aquecedor. Tem a função de controlar a temperatura da água sem a necessidade da intervenção humana (Fabichak \& Fabichak, 1985).

Filtro - Faz a filtragem da água retirando as impurezas. Existem vários tipos de filtros de acordo com a dimensão do aquário (Fabichak \& Fabichak, 1985).

Termômetro - Serve para verificar a temperatura da água que deve estar na faixa de $20^{\circ} \mathrm{C}$ a $26^{\circ} \mathrm{C}$ (Fabichak \& Fabichak, 1985).

Tubo Plástico - Serve para retirar a sujeira acumulada no fundo do aquário (Fabichak \& Fabichak, 1985). 
Tampa - Serve para tampar o aquário e como suporte para a lâmpada. É essencial que seja feita de madeira, para ficar leve mas resistente (Fabichak \& Fabichak, 1985).

Pinça - Serve para plantio para as espécies de plantas aquáticas (Botelho Filho; Oliveira, 1989).

Raspador - Serve para raspar as algas aderidas no vidro do aquário para mantê-los com características transparentes (Botelho Filho; Oliveira, 1989).

Comedores - Servem para colocação da alimentação (Botelho Filho; Oliveira, 1989).

Ninheira - Utilizado para a desova das fêmeas. Nem todas as espécies de peixes ornamentais necessitam de ninheiras (Botelho Filho; Oliveira, 1989).

Rede - Para apanhar os peixes sem machuca-los (Botelho Filho; Oliveira, 1989).

\section{Os microrganismos no aquário}

A associação dos aquários com os microrganismos é uma relação de simbiose única. Neste recipiente forma-se um ecossistema onde as bactérias possuem papel fundamental. A colônia de bactérias fixa-se na superfície do cascalho e posteriormente multiplicam-se e colonizam as camadas inferiores caso haja um bom teor de oxigênio. Quando a amônia encontra as bactérias começa um processo de reações químicas em dois estágios distintos. No primeiro estágio as bactérias nitrossomas, convertem a amônia em nitrito. 0 nitrito por sua vez é transformado em nitrato pelas bactérias nitrobacter, no segundo estágio (Botelho Filho; Oliveira, 1989; Fabichak \& Fabichak, 1985).

\section{CONCLUSÕES}

Existem vários tipos de filtros que podem ser usados com a mesma finalidade em um aquário. A qualidade da água sempre será o objetivo, e fator limitante na condução de um aquário. Sem dúvida alguma, a integração dos diferentes tipos de filtros existentes resultará em uma água de melhor qualidade final. Esse ecossistema depende não só dos filtros e sim de um bom 
Noronha, C.R.S., Moreira, G.L., Murilo, J.G. et al. O papel dos filtros e demais equipamentos de um aquário. PUBVET, Londrina, V. 2, N. 45, Art\#444, Nov2, 2008.

funcionamento de todos os equipamentos do aquário. E principalmente do bom senso do aquarista quanto sua condução e manejo.

\section{BIBLIOGRFIA CITADA}

ALCON - Indústria e Comércio de Alimentos Desidratados Alcon Ltda. Seu novo aquário. Camboriú, SC. 2000, 55p. Panfleto de distribuição gratuita.

BOTELHO, Gastão. Aquários. São Paulo: Editora NOBEL, 1997. 85p.

BOTELHO FILHO, Gastão da Fonsceca; OLIVEIRA, Nilson Araújo. A vida no aquário. $10^{\circ}$ ed. Ampliada, São Paulo: Editora NOBEL, 1989, 241p.

Coleção Animais de estimação. Peixes. Editora JB Indústria gráfica LTDA. Rio de Janeiro, 1986. 292p.

FABICHAK, Douglas; FABICHAK, Walter. Peixes de Aquário: criação, alimentação, doenças e espécies. $8^{\circ}$ Edição. São Paulo: Editora NOBEL, 1985, 71p.

VIDAL JUNIOR, Manuel Vazquez. Sistemas de produção de peixes ornamentais. Cadernos Técnicos de Veterinária e Zootecnia, Editora FEP-MVZ, Belo Horizonte, 2006. no 51, p6274. 